\title{
Phenomenon of financial pyramids: nature and design
}

\author{
Anzhu Allar Aleksandrovich \\ Department of Finance and Credit \\ Voronezh State Agricultural University named after \\ Emperor Peter the First \\ Voronezh, Russia \\ anjou@inbox.ru
}

\author{
Pshenichnikov Vladislav Vladimirovich \\ Department of Banks, Financial markets and Insurance \\ Saint-Petersburg State University \\ of Economics \\ Saint-Petersburg, Russia \\ wladwp@yandex.ru
}

\begin{abstract}
Annotation - The article is dedicated to the study of nature and design of financial pyramids. The mechanism for the appearance and models of financial pyramids, the brief review of their appearance and collapse in the global history and in modern Russia are considered. Fractal geometry is suggested for use as a method of a mathematical description of design of financial pyramids.
\end{abstract}

Key words - self-similarity; financial literacy; financial pyramid; fractal; fractal tree

\section{INTRODUCTION}

The Eastern proverb says: "Everything in the world is afraid of time, but time is afraid of the Pyramids." Over a hundred stone pyramids of pharaohs have been in Egypt for more than five thousand years. The largest of them, the Great Pyramid of Cheops, originally had a height of 146.6 meters, currently its height is about 138 meters. Assuming that this pyramid will continue to "grow» into the ground at the same speed, it will disappear from the surface of the Earth in about 78 thousand years. If one takes into account that the soil under the pyramid is condensed to the maximum extent and then the process of «ingrowth» slows down or completely ceases, then the Great Pyramid of Cheops (like all pyramids in this valley) can stand for millions maybe even billions of years.

Completely different perspectives can be foreseen for financial pyramids. The business schemes used in them require funds redistribution of those members who are at the «bottom» of the pyramid to those who are at a very «top». Investors are promised huge revenues due to contributions of other members who joined later. All members are persuaded that if they join before others, it will bring them closer to the «top» and consequently increase their chances of obtaining maximum benefit compared to others. The difference between the pyramid schemes and the real ones lays in the sources of payments. Whenever the amount of payments constantly exceeds the amount of surplus value that this business can provide this financial project is a pyramid [5].

The target of the article is to suggest the mathematics interpretation of financial pyramids design using fractal geometry tools.
The following objectives were set to achieve this target: using examples from the history of financial pyramids to reveal the nature of their appearance and business schemes depending on a model of a pyramid, to give a brief review of the practice of financial pyramids creation in the modern Russia, to show the capabilities of the mathematical description of financial pyramids design on the analogy with «fractal trees» structure.

\section{NATURE AND MODELS OF FINANCIAL PYRAMIDS}

The study of the nature of the financial pyramids according to their design allowed us to distinguish the following types: 1. Financial pyramid scheme Ponzi; 2. A multilevel pyramid; 3 . A masked pyramid.

1. Carlo Pietro Giovanni Guglielmo Tebaldi Ponzi Charles - the full name of the financial pyramids pioneer creator. The Italian immigrant came to the USA, having two and half dollars in a pocket, and created the most ingenious pyramid based on two hundred dollars borrowed from an acquainted furniture merchant. In other words, he did not even use a cent of his own money to create it. He came up with the idea: to start publishing an international magazine. Ponzi turned to a Spanish company with a proposal for cooperation. As a positive response, he received an international exchange coupon. This coupon could be exchanged by any person for stamps in the post office and mailed to the addressee. So that is how appeared an idea to earn on a difference between the prices of purchase and sale in various places which was named spatial arbitration. Let us give an example. Firm X purchases ore in India for its sale in Japan. The agent of firm $X$ in Japan searches for the buyer for 20 tons of ore and demands from the Indian branch to purchase this ore. The fact is that in India ore is bought at a lower price and in Japan it is sold at a higher price. The difference between a low purchase price and a high selling price is a way to generate income. Charles Ponzi wanted to do the same with international coupons. The purchase of a coupon in Spain at the price of one cent after its exchange in the US with the stamp was completed by the sale of this stamp for six cents.

The founder of this scheme invests his or her money, the first and second levels receive income from the funds of the founder of the pyramid. The recruiting of new investors is 
based on rumors and recommendations about the "know-how" of the organizer, which is supported by the words of people who have already made a profit. So, the pyramid becomes profitable, investors receive income from the funds raised from new members. Each investor of this pyramid enters it for profit and, since its organizer is only engaged in recruiting of new investors, the collapse of this scheme is directly proportional to the number of newly attracted investors. As it usually happens right after that the founder of the pyramid gets away with all the funds invested by the participants. Such financial pyramid brings a huge income only to its organizer.

2. Each participant of a multi-level scheme of financial pyramids makes a certain substantial contribution and after that the development of the pyramid boils down to the fact that its members are engaged in the search and recruitment of participants of the next level since their income directly depends on the number of new investors. As a rule, the «construction» of such pyramid ends at the fifth-sixth level since with each new step the recruitment of new investors becomes more and more problematic. The maximum income is received by the top of the pyramid and the first-second levels participants. The lifetime of such financial pyramid is short.

3. Masked financial pyramids are promoted as multi-level marketing business, in other words, such pyramids sell different goods or services. Participants come to this pyramid and search for people to whom they sell these goods or services. They are granted commissions for this. Goods and services are a cover for the firm in order to avoid suspicions and accusations of organizing a financial pyramid.

All listed financial pyramids are widely met in social networks. One has only to go to social networks to immediately get information about how to make quick money, the relevant links pop up to follow. There are successful investment funds, forecasts for the results of sports competitions, other ingenious ways to get people's money. In the same way, scammers operate under the guise of online stores: the buyer wants to receive the necessary goods, transfers a certain amount of money to the designated account. But as soon as a sufficient number of «investors» is collected, the organizer simply disappears with money. This «cunning» type of making money became especially widespread as a result of the Internet development: one by one, the financial pyramids began to appear in social networks. And this is natural since these pyramids are much easier to create than classic network companies. In the Internet, it is easier to recruit the pyramid participants transferring their finances by means of electronic money, not to mention the support of persuasive advertising, namely: invitations by mail, infinite pop-up windows on sites with tempting offers, spam, etc. In addition, it is possible to organize the financial pyramid anonymously with the Internet. And consequently, it becomes almost impossible to track the cash flows, to bring the organizers to legal responsibility or to return the money. It makes us think that the Internet offers the most favorable conditions for those wishing to earn quick money.

As an example, one can name a number of Internet pyramids: Global, Intergold Recyclix, MMM 2016, Currency
Systems. According to official statistics, there were about 2500 financial pyramids of various models in the Russian Federation over the last 15 years. In the Arab States, the death penalty is a punishment for organizing financial pyramids. Surely, it is not the best solution for deprivation of life, but it is the most effective and sufficient way to warn the citizens of the possible danger, threatening their financial means. But the authors suppose that the most effective measures are activities organized to increase financial literacy and awareness of the population about the constantly emerging new schemes of financial pyramids.

In particular, special attention should be given to the typical features of financial pyramids thanks to which it becomes possible to distinguish them from the mass of other companies and organizations. These include:

- Absence of a license from regulatory bodies to carry out activities to raise funds of the population.

- Promise of high profitability, several times exceeding the market level; guarantee of profitability (which is prohibited in the stock market).

- Massive advertising in the media and the Internet with the promise of high profitability.

- Lack of any information about the financial situation of the organization.

- Payments to new participants from funds previously invested by other participants.

- Lack of own fixed assets, other high-value assets.

- The lack of an accurate definition of the type of activity of the organization and sources of income.

Availability of at least a few of the mentioned above signs immediately casts doubt on the legitimacy of the organization. Nevertheless, is it possible to make money with the pyramid? Of course. But only when a person came there one of the first of what the person cannot be sure. If one already found oneself in a pyramidal organization, do not panic. The best and only way out is to apply to law enforcement agencies, and with their help it may be possible to return a portion of the invested money. In most cases, money invested in financial pyramids disappear without a trace.

\section{FINANCIAL PYRAMIDS IN MODERN RUSSIA}

The pioneers of pyramids building in modern Russia were the following companies:

- In 1992, CJSC «Russkiy Dom Selenga» was founded in Volgograd city by Aleksandr Salomadin and Sergey Gruzin. The losses of 2.4 million investors amounted to more than 2.8 trillion non-denominated rubles.

- In 1993, OJSC «MMM», the most famous Russian pyramid, was organized by the citizen of the Russian capital Sergey Mavrodi; the total number of its investors ran up to 15 million people; the losses of the investors have not been counted by now. 
- In 1993, LLP «Invest company «Khopyor-Invest» was founded in the same manner as «Russkiy Dom Selenga» in Volgograd city by Liya Konstantinova and Oleg Suzdaltsev. It appeared that 4 million investors were recruited. The amount of losses reached 3 trillion non-denominated rubles.

- In 1993, the company «Vlastelina», founded by Valentina Solovyova in Moscow Region, embezzled funds of investors in the amount of more than 500 billion rubles; there were 16.5 thousand investors involved.

- In 1996, the bank «Chara», founded by Vladimir Radchuk, turned into a financial pyramid, the debt amounted to 131 billion rubles; there were more than 70 thousand victims [10].

Every day more and more participants are getting involved in the pyramids. In 2017, the world «celebrated» $25^{\text {th }}$ anniversary of the appearance of financial pyramids in the Russian Federation.

In the first quarter of 2017, the Bank of Russia identified 31 financial pyramids, which is 1.6 times less than the same period of the last year -50 financial pyramids. As statistics show, the number of pyramids, as well as the damage caused by their actions (Figure 2), is decreasing (Figure 1) [2].

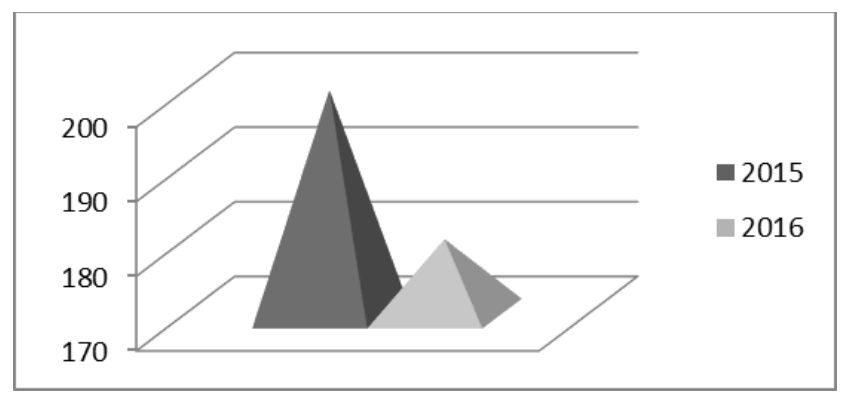

Fig. 1. The number of functioning pyramids in the Russian Federation in 2015-2016

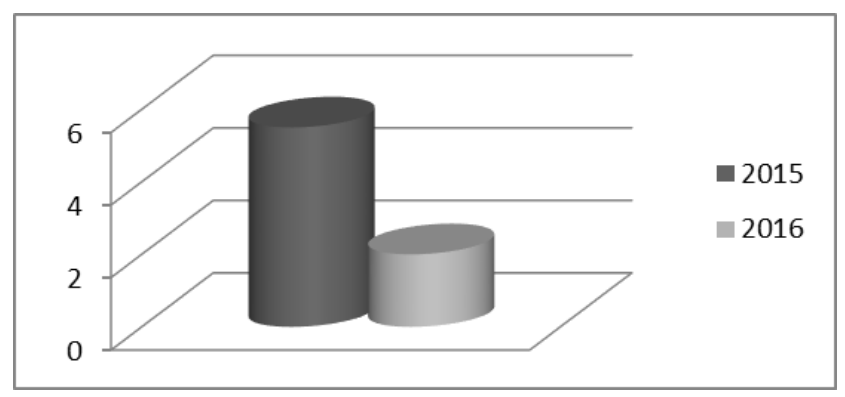

Fig. 2. Damage, caused by financial pyramids in the Russian Federation in 2015-2016, billion rubles

In March 2014, the General Directorate for countering unfair practices in the open market was created in the structure of the Bank of Russia. Among its tasks is to identify the activities of organizations that have signs of «financial pyramids». The Directorate analyzes the information received by the Bank of Russia, interacts with law enforcement agencies, provides them with advisory assistance, and summarizes the law enforcement practice in this area.

In perspective, the Bank of Russia sets a goal to create a system for monitoring and identifying the activities of the «financial pyramids» at early stages, which will allow one to react promptly to emerging threats to the population. It is assumed that the department will become a center that coordinates the activities of state bodies, including law enforcement, in the sphere of counteraction to the activities of the «financial pyramids». At the same time, the work of the Bank of Russia will be aimed not only at identifying and suppressing the already existing «financial pyramids», but also at preventing their occurrence.

On March $30^{\text {th }}, 2016$, the President of the Russian Federation V.V. Putin signed Federal Law No. 78-FZ dated March 30" 2016 "On Amendments to the Criminal Code of the Russian Federation and Article 151 of the Code of Criminal Procedure of the Russian Federation". Article 172.2 came into force. From now on the organization of pyramids is punishable with a fine of up to one million rubles, or forced labor for up to four years, or imprisonment for the same term with restriction of freedom for a period of up to one year or without it. And in a particularly large amount, it is punishable by a fine of up to 1500 thousand rubles, or by forced labor for a period of up to five years, or by imprisonment for up to six years with restriction of freedom for up to two years or without it.

To more accurately determine the attitude of citizens of Russia to definition and identification of the organization as a financial pyramid, let us turn to the results of a survey conducted by the multifunctional analytical center "NAFI", whose customers are, in particular, the Ministry of Finance of the Russian Federation, the Bank of Russia, the largest commercial banks, insurance, investment and consulting companies. The results of the survey are presented in Table 1 [3].

Initiative all-Russia survey "NAFI" was performed in 2015. 1600 people were interviewed in 132 residential places in 46 regions of Russia. Statistical error did not exceed 3,4\%. The following question was asked during the survey: «Imagine, one had to make a decision about investing money and after studying the existing offer in the market, one has found several options. Which of the options, in your opinion, may turn out to be a "financial pyramid"?

The proportion of citizens who correctly identified the signs of the financial pyramid (guaranteed $35 \%$ growth in incomes in one year) stays practically the same - about a quarter during seven years of survey performance $(28 \%$ in 2008 and $27 \%$ in 2015). However, the number of people seeing the features of the pyramid in the bank offering deposits at $12 \%$ annual rate has decreased (4\% in 2015 versus $11 \%$ in 2011). A unit investment fund reporting a $35 \%$ return on its units for the previous year was suspected to have features of financial pyramids by $13 \%$ of people interviewed in 2015. General fund of banking management offering equity certificates is still considered to be a financial pyramid by $3 \%$ of interviewees. 
TABLE I. DISTRIBUTION OF INTERVIEWEES ANSWERS BY VARIANTS, \%

\begin{tabular}{|l|c|c|c|c|c|}
\hline \multicolumn{1}{|c|}{ Variants } & 2008 & $\mathbf{2 0 0 9}$ & $\mathbf{2 0 1 0}$ & $\mathbf{2 0 1 1}$ & $\mathbf{2 0 1 5}$ \\
\hline $\begin{array}{l}\text { Financial } \\
\text { organization, } \\
\text { offering prospect of } \\
\text { guaranteed 35\% } \\
\text { growth in incomes in } \\
\text { one year }\end{array}$ & 28 & 22 & 28 & 23 & 27 \\
\hline $\begin{array}{l}\text { General fund of } \\
\text { banking management } \\
\text { offering equity } \\
\text { certificates offering }\end{array}$ & 3 & 2 & 4 & 4 & 3 \\
\hline $\begin{array}{l}\text { Bank 12\% } \\
\text { deposits at } \\
\text { annual rate }\end{array}$ & 7 & 8 & 7 & 11 & 4 \\
\hline $\begin{array}{l}\text { Unit investment fund } \\
\text { reporting a 35\% } \\
\text { return on its units for } \\
\text { the previous year }\end{array}$ & 10 & 8 & 8 & 9 & 13 \\
\hline $\begin{array}{l}\text { All listed variants } \\
\text { variants of listed } \\
\text { answer know/ No }\end{array}$ & 12 & 6 & 7 & 35 & 26 \\
\hline
\end{tabular}

From year to year, the number of Russians regarding all the banking instruments presented in Table 1 as financial pyramids is increasing (10\% in 2009 and $18 \%$ in 2015), which indicates a general misunderstanding and distrust of the population towards financial instruments.

\section{FRACTAL GEOMETRY AS A METHOD OF DESCRIPTION OF THE STRUCTURE OF FINANCIAL PYRAMID}

In his «Introduction to Cybernetics», William R. Ashby [1] wrote: «Cybernetics has the same attitude to real machines electronic, mechanical, nervous and economic - like geometry to real objects in our terrestrial space. There was a time when "geometry" was understood as a relationship that can be visualized on three-dimensional bodies or $2 \mathrm{D}$ drawings. The forms that existed on the Earth in animals, plants, minerals were more numerous and richer in properties than the forms that existed in elementary geometry. In those days, the form suggested by geometry, but not allowing visual representation in ordinary space, was questionable or unacceptable. The ordinary space dominated geometry.

Now the situation is completely different. Geometry exists by its own right, thanks to its own forces. It can now accurately and consistently consider the diversity of forms and spaces, far exceeding everything that earth space can give. Now geometry contains terrestrial forms, and not vice versa, for terrestrial forms are only particular cases in comprehensive geometry» [4].

As one of the mathematical description methods of the financial pyramids design, the authors made a choice in favor of fractal geometry developed by the French mathematician Benoit Mandelbrot [7].

«Fractals are objects (mathematical, natural or man-made) that are called irregular, rough, porous or fractured, and these fractals have the specified properties of the same degree on any scale. One can say that the form of these objects does not change regardless of the fact that they are studied at the short or long distance. In a financial sense, as one will see shortly, fractality means variability, which is the same at all levels.

The study of such objects is the task of fractal geometry. It closely adjoins the neighboring areas of human activity, as a result of which one can speak of the existence of the geometry of the spontaneous case, for example, and the geometry of chaotic determinism.

The authors are talking, in fact, not about a new theory and, especially, not about a new discipline, but about a new method. Its original aim coincides with the goal of any science: to seek elements of order that can clarify the chaos of those messages that a person receives from his senses» [6].

Many of those structures that were once considered irregular, rough, porous or fractured, and which fractal geometry turned into useful tools of scientific cognition, deserve to be judged as pre-fractal, i.e. preceding fractals. Two categories of prefractals deserve special attention: selfsimilarity and self-affinity [8]

According to the concept of linear self-similarity, B. Mandelbrot offers the following treatment of self-similarity. "An object is called self-similar if its "whole" (the object itself taken as a whole) can be divided into "parts", each of which comes from the whole through the transformation of similarity, that is, reduction or linear compression. Such reduction can disintegrate into homothety, which is sometimes accompanied by transfer, reflection, or rotation. The latter component becomes crucial when one moves from selfsimilarity to self-affinity. Such object is said to be "invariant in relation to a family of reductions". (Reductions cannot be arbitrary, they must form a «semigroup»).

From the mathematical point of view, the reduction process can be repeated an arbitrary number of times. It immediately follows that a self-similar mathematical object consists of infinitesimal details.

Similarly, «self-similarity» can mean that any part of an object that is appropriately «enlarged» can be put over its most part. Repeating this process an indefinite number of times, one can see that such an object, called «invariant concerning increase», has an infinitely large size for sure. Meanwhile, the existing fractals are limited and do not have infinitesimal details» [6].

In order to graphically illustrate self-similarity and selfaffinity in fractal geometry, let us give examples of two objects, each of which is a fractal.

The first object, the "envelope" curve, was proposed by the Swedish mathematician Niels Fabian Helge von Koch in 1904, later called the Koch curve or "snowflake". In order to construct the inner area of the third of "snowflake", one must take the steps shown in Figure 3, where the successive 
approximations of the curve are represented by the boundary between black and white colors.

Let us start with a segment of unit length, which is divided into three parts. To the middle of these parts, two other segments are applied so that there is an equilateral triangle. The same can be done with segments of length $1 / 3,1 / 9,1 / 27$, and so on. After $\mathrm{n}$ constructions of equilateral triangles, a broken line is obtained, which is the boundary of the object depicted in Figure 3. Its length is $4 / 3$ to the $n$ power. The boundary tends to a limit of infinite length.

The second object is the "space-filling" movement that passes through the entire inner area of the Koch curve, which was subsequently called "space-filling" or a "snowflake". It was proposed by B. Mandelbrot in 1977, who named it in imitation of the term "Brownian motion"; to commemorate the merits of the Italian mathematician Giuseppe Peano (18581931), it was called the "Peano movement". It is a movement, which eventually passes through every point of the plane. For some very deep reasons, some points of the plane are visited several times, but this movement does not have selfintersections.

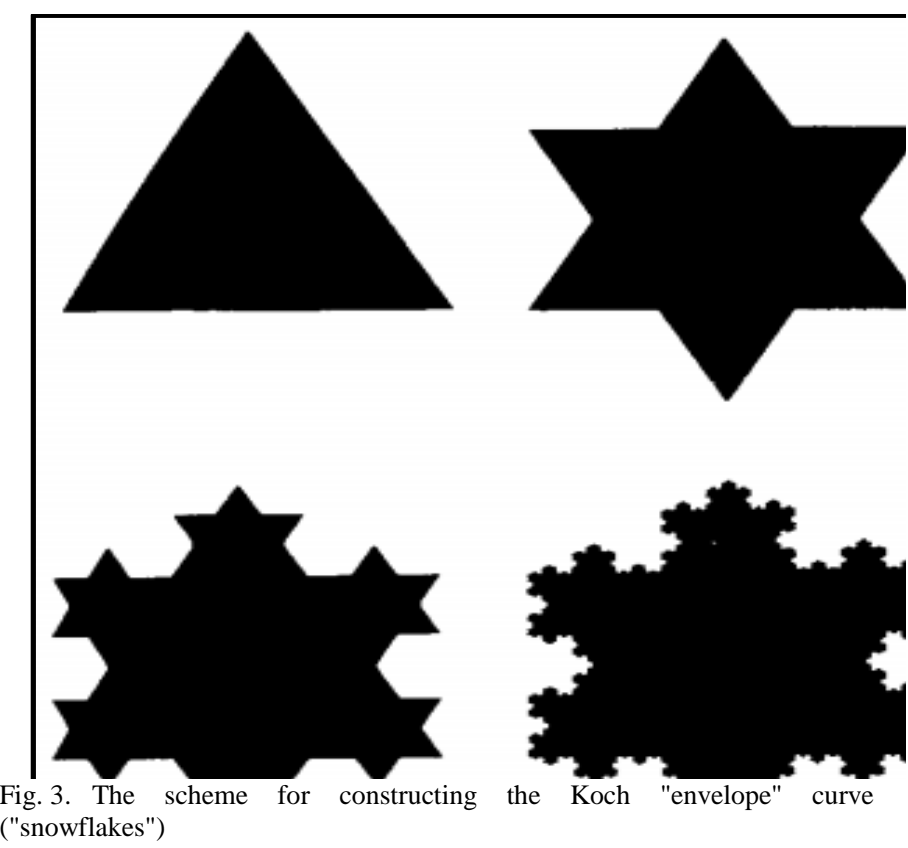

Figures 4 and 5 show the construction of the "spacefilling" "Peano movement" curve before rounding off the corners and after it, respectively.
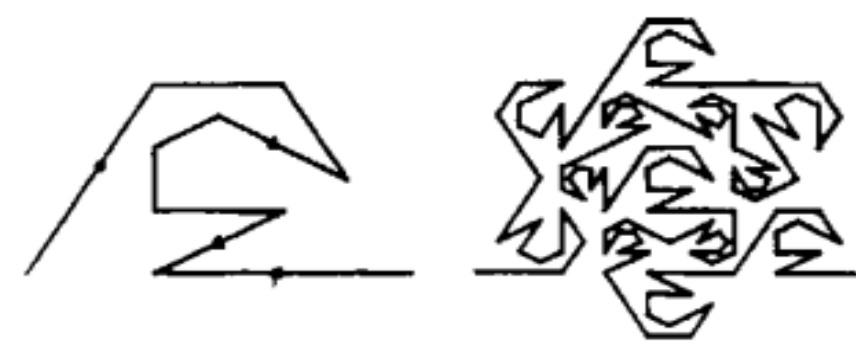

Fig. 4. The scheme for constructing the "space-filling" "Peano movement" curve
Figure 4 shows only the principle of construction, which consists in applying a generator, which includes thirteen segments (left) in a single section. So that the approximating curves did not have double points, the reduced copies of the generator must be placed in a very specific way (as shown on the right). Each reduced part can be replaced by a symmetric one, which is relative to a line. In this case, the positions of the parts are chosen, based on the aesthetic considerations of B. Mandelbrot, in order to make Figure 5 as harmonious as possible and more similar to the wave in shape [9].

Approximating curve B in Figure 5 consists of 13 circular arcs. On approximating curve $\mathrm{C}$, each of these arcs is replaced by a reduced copy of the entire curve. These copies are made in black and white colors and represent "positive" on convex arcs (as in the upper part of B) and "negative" on the concave. Thus, approximating curve $\mathrm{C}$ consists of $13^{2}$ arcs, the same procedure is performed with each of them, etc.

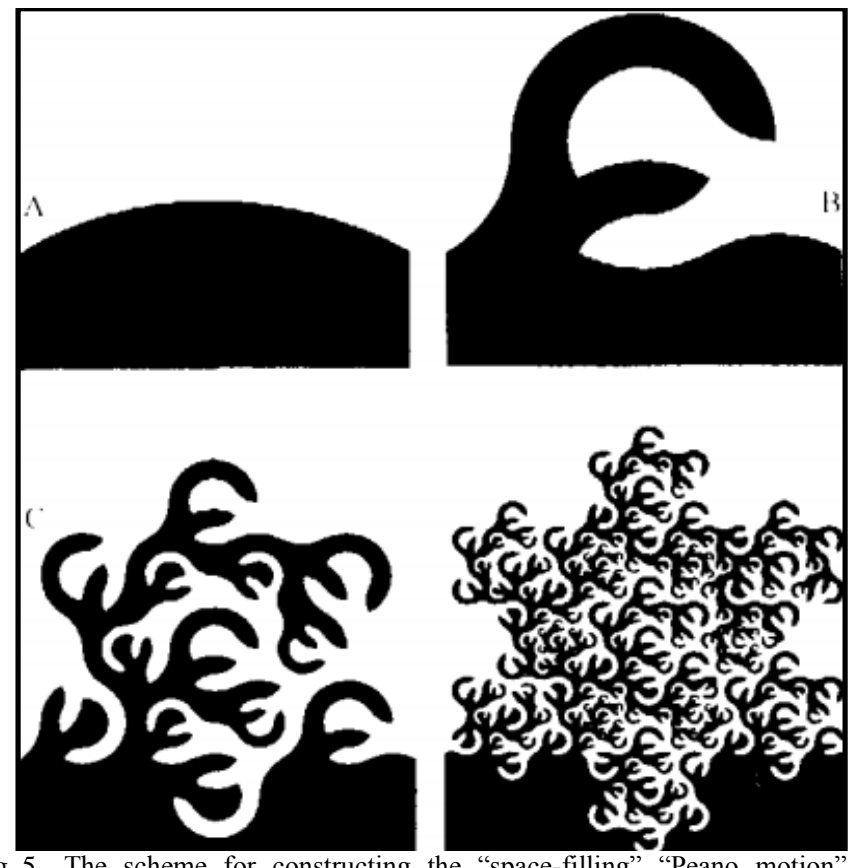

Fig. 5. The scheme for constructing the "space-filling" "Peano motion" curve, where each segment of the line is replaced by an arc of the size of a sixth of the circle

Each subsequent stage of construction leads to the creation of a more perfect prefractal approximation in the form of a broken curve composed of smaller and smaller segments. These segments are gradually getting closer to vertical. With such approximation, the prefractal at each stage of construction is stretched in a fixed ratio, greater than one, just as at each stage of construction the "snowflake" is stretched in the ratio of $4 / 3$. Thus, the model proposed in Figure 5 demonstrates a self-affine function. Linear self-affinity excludes rotation, but its operations break up into transport and reduction, subject to a much smaller number of limitations than in case of self-similarity.

The binding thread between the concept of fractal and financial pyramids was the idea that some phenomena of the world around us have the same structure being viewed both near and far away, that is, at any scale, when the picture is 
enlarged in order to consider any fragments in more detail only change minor details. So, each small section of the fractal is the key to the whole design. This idea was called the «scaling principle» in the fractal geometry. It can be observed when elements that are far from each other in appearance coalesce.

Among the rich variety of fractals, fractal trees are the most suitable for the mathematical description of the construction of financial pyramids. A vivid example of a constructive fractal is a binary tree. It is built according to the following principle: at each level, the vertical line is divided into two with a reduction factor of $1 / 2$. Such ramified fractals are called dendrites («dendron» is a Greek word for a tree). What strikes the eye when considering a fractal-dendrite is self-similarity: each branch separately represents the whole tree. And self-similarity is, as it has been already seen, one of the main properties of fractals. Splitting a set into groups of two elements or combining into groups of two elements is typical for a binary number system. This division is often used in practice, for example, in sports team competitions. Teams are split in pairs, the winner is determined in the pair, the remaining teams are split again, and so on, until the winning team remains. This way, it is possible to obtain an inverted binary tree. A binary tree is one of the simplest examples of a family of fractals, in which the structure of the scale of notation is represented geometrically. One can also build a ternary, quaternary, etc. trees. To build a V-tree, let us use a fragment of the form of letter $\mathrm{V}$. The principle of construction is seen in Figure 6.

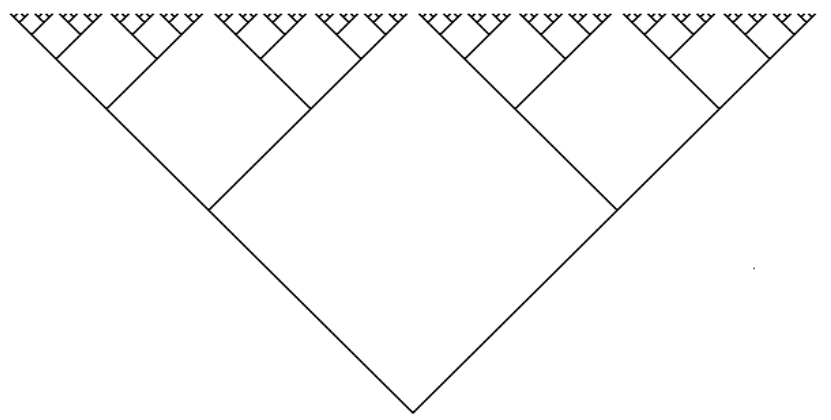

Fig. 6. A binary tree

Similarly, the ternary, quaternary, etc. trees can be built. Below there is a triad tree (Figure 7), which can illustrate the design of a multi-level financial pyramid and its building program even more accurately (Figure 8).

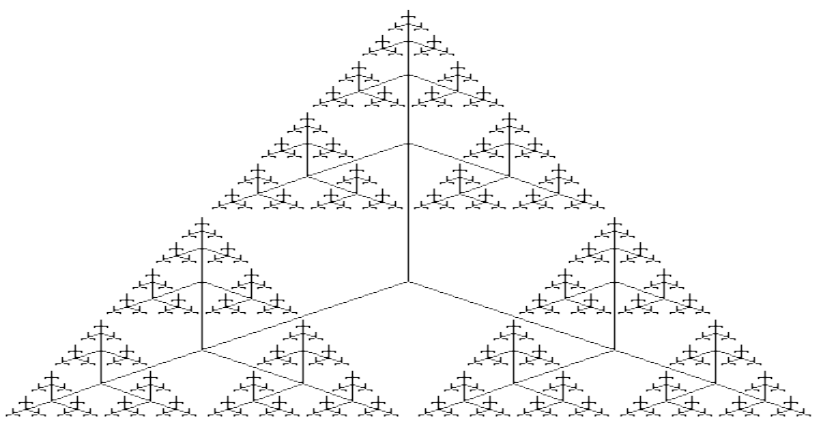

Fig. 7. A ternary tree
The obtained ternary tree is nothing else than the Sierpinski triangle. This entertaining object was invented in 1915 by the Polish mathematician Vaclav Serpinsky. The Sierpinski triangle became one of the earliest known examples of fractals. There are several ways to build it. One of them represents the following process. Let us take a continuous equilateral triangle; at the first step, it is necessary to remove an inverted triangle from the center. At the second step, let us remove three inverted triangles from the three remaining triangles. Continuing this process, at the $\mathrm{n}^{\text {th }}$ step, let us remove $3^{\mathrm{n}}-1$ inverted triangles from the centers of $3^{\mathrm{n}-1}$ remaining triangles. There will be no end to this process and no clear spot can be seen on it, but it will not disintegrate. An object consisting of nothing but voids will be obtained.

The Sierpinski triangle consists of three copies of itself, each half as small. The mutual arrangement of them is such that if the grid cells are reduced by half, the number of squares intersecting with the fractal will triple. That is, $\mathrm{N}(\delta / 2)=3 \mathrm{~N}(\delta)$. If the initial cell size was 1 , and $\mathrm{N}_{0}$ of them intersected with the fractal $\left(\mathrm{N}(1)=\mathrm{N}_{0}\right)$, then $\mathrm{N}(1 / 2)=3 \mathrm{~N}_{0}, \mathrm{~N}(1 / 4)=3^{2} \mathrm{~N}_{0}, \ldots$, $\mathrm{N}\left(1 / 2^{\mathrm{k}}\right)=3^{\mathrm{k}} \mathrm{N}_{0}$. Hence, $\mathrm{N}(\delta)$ is proportional to $\left(\frac{1}{\delta}\right)^{\log _{2} 3}$, and by definition of fractal dimension, it is exactly $\log _{2} 3$.

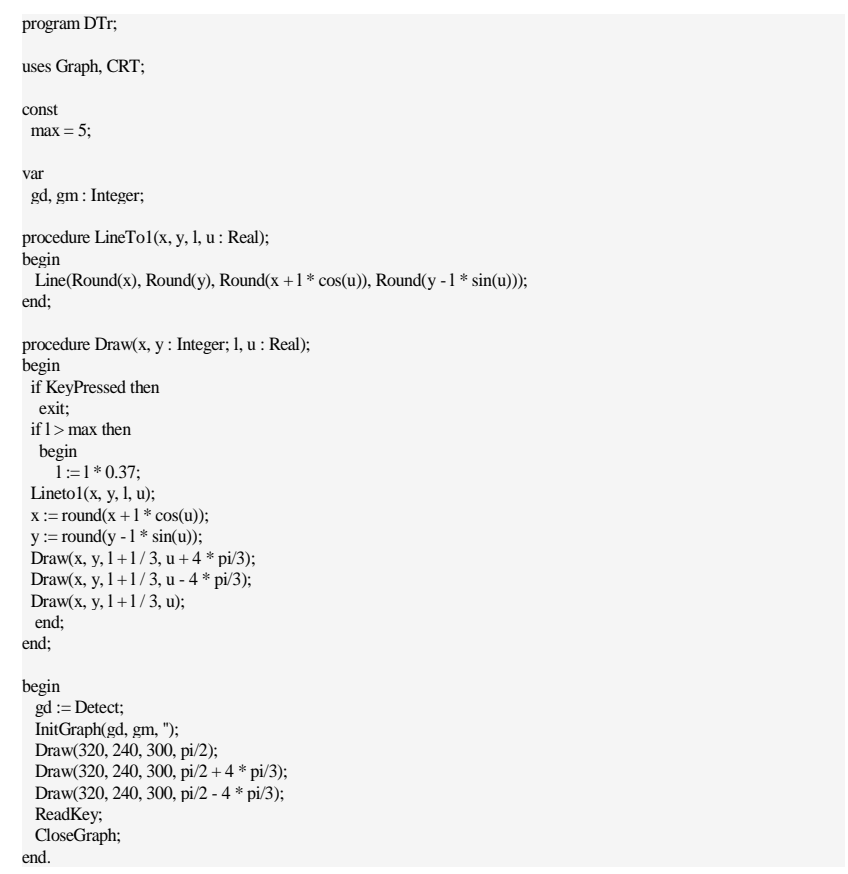

Fig. 8. A program of building of a ternary tree

Thus, the mathematical tool, describing proportions of the Sierpinski triangle, in our opinion, may be used for identification of a potential financial pyramid with a similar correlation between the amount of income and the amount of investment.

\section{CONCLUSION}

The existence of financial pyramids is inexorably associated with such functions of finance as redistribution, concentration and centralization of capital. The phenomenon of financial pyramids should be considered as the reverse side of the public significance of the above-listed functions of 
finance. In the process of creation and use of centralized and decentralized funds of state capital, the political, protective, socio-economic and other functions of the state are realized. Whereas in the process of creating and ruining the financial pyramids, an appropriation of the money savings of the general population is realized by a small group of organizers of financial pyramids. In the first case, the functions of finance serve the public good; in the second case - the private interest of individuals.

The phenomenon of financial pyramids leaves a negative imprint on the political, socio-economic and investment portrait of the country if it does not take sufficient measures to prevent the causes of their occurrence. The statutory ban on the operation of financial pyramids and the criminal prosecution of their creators cannot be recognized as absolute protective guarantees for the population from the actions of the organizers of the pyramids outside the legal field. A larger role is given here to financial literacy of general population and availability of an easy-to-use tool for early identification of potential financial pyramids. Such tools are needed not only for ordinary citizens who do not possess professional knowledge in the field of finance, but also for bodies for licensing and supervision of financial activities.

Numerous existing forms (including financial pyramids) are so occasional or irregular that the complexity of their nature not only quantitatively but also qualitatively exceeds everything that Euclid's geometry allows. The authors propose considering financial pyramids as fractal objects. This allows us to describe them in a sufficiently effective way, making it possible to simulate such real objects and to create their duplicates using very simple mathematical formulas.

\section{References}

[1] W.R. Ashby, An Introduction to Cybernetics. London: Chapman \& Hall, 1956.

[2] The Bank of Russia uncovered 31 financial pyramids during the first quarter. [Internet source] Data access mode: https://lenta.ru/news/2017/05/12/cbr/

[3] Watch out! Financial pyramids. [Internet source] Data access mode: http://nafi.ru/analytics/ostorozhno-finansovye-piramidy/

[4] A.I. Dyomin, Information theory of economics: Macromodel. The $3^{\text {rd }}$ edition. Moscow: KomKniga, 2010.

[5] A.M. Korotchenkov, D.A. Vinogradov, «Market failures. Depts, deficits, crisises, defolts, financial pyramids, financial bubbles, bank panics - are links in a chain», Moscow: LLC "Prospekt", 2015.

[6] B. Mandelbrot, Fractals, fate and finance. Moscow-Izhevks: RDE «Regular and classical dynamics», 2004.

[7] B.B. Mandelbrot, The Fractal Geometry of Nature, New York: Freeman, 1982.

[8] B.B. Mandelbrot, Fractal and Scaling in Finance: Discontinuity, Concentration, Risk. New York: Springer-Verlag, 1997.

[9] B.B. Mandelbrot, Fractal \& Self-affinity: R / S, 1 / f, Global Dependence, Relief \& Rivers. New York: Springer-Verlag, 1997.

[10] T. Maslova, «Great combinators of the $90^{\text {th }}$ ». [Internet source] Data access mode: https://credits.ru/publications/364371/velikiekombinatory-90-yh. (date of access: 26.05.2017). 